\title{
Spatiotemporal Variations in Ambient Ultrafine Particles and the Incidence of Childhood Asthma
}

Eric Lavigne a, b, Jessy Donelle ${ }^{\text {c, d }}$, Marianne Hatzopoulou ${ }^{\mathrm{e}}$, Keith Van Ryswyk ${ }^{\text {a }}$, Aaron van Donkelaar ${ }^{\mathrm{f}}$ Randall V. Martin f, g, Hong Chen h, i, j, k, David M. Stieb ${ }^{\text {l, b }}$, Antonio Gasparrini ${ }^{\mathrm{m}}$, Eric Crighton $^{\mathrm{c}, \mathrm{n}}$, Abdool S. Yasseen III ${ }^{\mathrm{o}}$, Richard T. Burnett ${ }^{\mathrm{h}}$, Mark Walker ${ }^{\mathrm{o}, \mathrm{p}, \mathrm{q}}{ }^{\text {and Scott }}$ Weichenthal ${ }^{\mathrm{a}, \mathrm{r}}$

${ }^{a}$ Air Health Science Division, Health Canada, Ottawa, Ontario, Canada

${ }^{\mathrm{b}}$ School of Epidemiology, Public Health and Preventive Medicine, University of Ottawa, Ottawa, Ontario, Canada

${ }^{\mathrm{c}}$ Institute for Clinical Evaluative Sciences, Ottawa, Ontario, Canada

${ }^{\mathrm{d}}$ Ottawa Hospital Research Institute, Ottawa, Ontario, Canada

${ }^{\mathrm{e}}$ Department of Civil Engineering, University of Toronto, Toronto, Canada

${ }^{\mathrm{f}}$ Department of Physics and Atmospheric Science, Dalhousie University, Halifax, Nova Scotia, Canada

${ }^{g}$ Harvard-Smithsonian Centre for Astrophysics, Cambridge, Massachusetts, USA

${ }^{\text {h }}$ Population Studies Division, Health Canada, Ottawa, Ontario, Canada

i Public Health Ontario, Toronto, Ontario, Canada

${ }^{j}$ Dalla Lana School of Public Health, University of Toronto, Toronto, Ontario, Canada

${ }^{\mathrm{k}}$ Institute for Clinical Evaluative Sciences, Toronto, Ontario, Canada

${ }^{1}$ Population Studies Division, Health Canada, Vancouver, British Columbia, Canada

${ }^{\mathrm{m}}$ Department of Public Health, Environments and Society, London School of Hygiene \& Tropical Medicine, UK

${ }^{n}$ Centre for Statistical Methodology, London School of Hygiene \& Tropical Medicine, UK

${ }^{\mathrm{n}}$ Department of Geography, Environment and Geomatics, University of Ottawa, Ottawa, Ontario, Canada

${ }^{\circ}$ Better Outcomes Registry and Network Ontario, Ottawa, Ontario, Canada

${ }^{\mathrm{p}}$ Children's Hospital of Eastern Ontario Research Institute, Ottawa, Ontario, Canada

${ }^{\mathrm{q}}$ Department of Obstetrics and Gynecology, University of Ottawa, Ottawa, Ontario, Canada

${ }^{\mathrm{r}}$ Department of Epidemiology, Biostatistics and Occupational Health, McGill University,

Montreal, Quebec, Canada

\section{Corresponding author}

Eric Lavigne, PhD, Air Health Science Division, Health Canada

269 Laurier Avenue West, Mail stop 4903B, Ottawa, Ontario, Canada, K1A 0K9

Telephone: 613-948-3686; E-mail: eric.lavigne@ canada.ca

\section{Author contributions}

Author Contributions: E.L. takes responsibility for the integrity of the data analysis and the accuracy of the data analysis, and had authority over manuscript preparation and the decision to submit the manuscript for publication. J.D. had full access to all of the data in the study. Study concept and design, E.L., J.D., H.C., D.M.S, R.T.B., and S.W. Acquisition, analysis, or interpretation of data, E.L., J.D., M.H., K.V.R., A.V.D., R.V.M., H.C., D.M.S., A.G., E.C., A.S.Y., R.T.B., M.W., and S.W. Drafting of the manuscript, E.L. and S.W. Critical revision of 
the manuscript for important intellectual content, all authors. Statistical analysis, E.L. and J.D. Study supervision, E.L. and S.W.

Funding: This study was funded by the Clean Air Regulatory Agenda program of Health Canada.

Running head: Ultrafine particles and childhood asthma incidence

Descriptor: 6.1 Air Pollution: Epidemiology

Word count: 3490

At a Glance Commentary:

Scientific Knowledge on the Subject: Ambient fine particulate matter (PM2.5) exposure in utero has been associated with the development of childhood asthma. However, little is known regarding the impact of ambient ultrafine particles $(<0.1 \mu \mathrm{m})$ (UFPs) on childhood asthma development

What this Study Adds to the Field: Our findings suggest that UFPs exposure during the second trimester of pregnancy was associated with an increased risk of developing asthma in children before age 6 independent of other air pollutants including $\mathrm{NO}_{2}$ and $\mathrm{PM}_{2.5}$. These findings highlight the need for further research on the effects of UFPs during the perinatal period on respiratory health in children.

Online Data Supplement: This article has an online data supplement, which is accessible from this issue's table of content online at www.atsjournls.org 


\section{ABSTRACT}

Rationale: Little is known regarding the impact of ambient ultrafine particles $(<0.1 \mu \mathrm{m})$ (UFPs) on childhood asthma development. Objective: To examine the association between prenatal and early postnatal life exposure to UFPs and development of childhood asthma. Methods: A total of 160,641 singleton live births occurring in the City of Toronto, Canada between April $1^{\text {st }} 2006$ and March $31^{\text {st }} 2012$ were identified from a birth registry. Associations between exposure to ambient air pollutants and childhood asthma incidence (up to age 6) were estimated using random-effects Cox proportional hazards models, adjusting for personal- and neighborhood-level covariates. We investigated both single- and multi-pollutant models accounting for co-exposures to $\mathrm{PM}_{2.5}$ and $\mathrm{NO}_{2}$. Measurements and Main Results: We identified 27,062 children with incident asthma diagnosis during the follow-up. In adjusted models, second trimester exposure to UFPs (Hazard Ratio (HR) per interquartile (IQR) increase $=1.09,95 \%$ CI: $1.06-1.12)$ was associated with asthma incidence. In models additionally adjusted for $\mathrm{PM}_{2.5}$ and $\mathrm{NO}_{2}$, UFPs exposure during the second trimester of pregnancy remained positively associated with childhood asthma incidence (HR per IQR increase $=1.05,95 \%$ CI: $1.01-1.09)$. Conclusion: This is the first study to evaluate the association between perinatal exposure to UFPs and the incidence of childhood asthma. Exposure to UFPs during a critical period of lung development was linked to the onset of asthma in children, independent of $\mathrm{PM}_{2.5}$ and $\mathrm{NO}_{2}$.

\section{Abstract word count: 229}

Key words: ultrafine particle, fine particulate matter, asthma, perinatal exposure, sensitive windows 


\section{Introduction}

The prevalence of asthma in children has been increasing worldwide over the last decades (1-3). Evidence links ambient air pollution exposures during pregnancy and early life with lung function deficits in children (4-7) as well as childhood asthma incidence (8-18). While most studies have focused on traffic-related air pollutants such as nitrogen oxides $\left(\mathrm{NO}_{\mathrm{x}}\right)$ and particulate matter (PM), there is still considerable uncertainty as to whether these pollutants are primarily responsible for the observed adverse effects. In fact, increased attention is being directed towards ultrafine particles $(\leq 0.1$ micrometers in diameter; UFPs), which are produced in large numbers by diesel vehicles and other combustion processes (19), but little is known regarding the impact of UFPs on childhood asthma incidence.

A small number of studies have reported positive associations between short term exposure to UFPs and respiratory health in children (20-26). However, to date, no epidemiological study has investigated the effect of longer-term exposure to UFPs during the perinatal period on the incidence of childhood asthma. Recently, a study among 8 to 11 -year-old school children in Brisbane, Australia found that annual average exposure to UFPs was associated with systemic inflammation, and airway inflammation specifically among atopic individuals (27). This is consistent with the fact that UFPs can penetrate deep into peripheral airways and alveoli and, subsequently affect children's health (19). In fact, exposure to UFPs during pregnancy may impact important phases of lung development which can translate into later risk of developing asthma (10, 28-30). Therefore, additional evidence is required in order to better characterize the impact of UFPs on respiratory health in children, which can have important implications for the establishment of ambient air quality standards. 
We conducted a population-based cohort study in Toronto, Canada to evaluate the association between UFP exposures during pregnancy and early postnatal life and childhood asthma incidence. We also evaluated if ambient UFPs are independently associated with childhood asthma incidence after adjusting for nitrogen dioxide $\left(\mathrm{NO}_{2}\right)$ and particulate matter with aerodynamic diameters $\leq 2.5 \mu \mathrm{m}\left(\mathrm{PM}_{2.5}\right)$.

\section{Methods}

\section{Study Population and Design}

Data on singleton live births between April $1^{\text {st }} 2006$ and March $31^{\text {st }} 2012$ from a cohort of women who have birth in Toronto, Canada was used. We obtained mother-infant pair data from the Better Outcomes Registry \& Network (BORN) Ontario, a province wide birth registry that captures perinatal health information (31). It was previously shown that $96 \%$ of all births delivered in Ontario were captured in BORN (31). In addition, ascertainment of births improved from approximately $89 \%$ of births in Ontario in the 2006-2007 fiscal year to $100 \%$ of births in the 2010-2011 and 2011-2012 fiscal years. We used the Postal Code Conversion File Plus $(\mathrm{PCCF}+)$ to obtain the geographic coordinates of maternal place(s) of residence based on residential postal code(s) reported in health administrative data. Linkages of health administrative data was conducted at the Institute for Clinical Evaluative Sciences (ICES) in Ontario, Canada using encrypted unique identifiers. We excluded from the study population pregnancies with residential postal codes outside Toronto, missing postal code value, those without a valid health card number, those with missing date of birth and those with missing sex 
information. We obtained information from the BORN database on first trimester ultrasound dating and the mother's last menstrual period in order to establish gestational age.

\section{Ascertainment of Asthma Incidence}

Incident cases of childhood asthma (International Classification of Diseases [ICD]-10: J45) were identified based on a previously published case algorithm using the Ontario ASTHMA cohort database (32). We identified incidence cases between birth and $<6$ years of age $(10,12)$ for the time period of April $1^{\text {st }} 2006$ to March $31^{\text {st }}$ 2015. Pregnant mothers who had a history of asthma were identified using the Ontario ASTHMA database (33).

\section{Exposure Assessment for Ambient Air Pollutants}

Ambient air pollutant concentrations were assigned based on the geographical location(s) of each participant's residential postal codes. In Toronto, 6-character postal codes are generally represented by one side of a city block or a large apartment complex. For each pollutant, we assigned exposure during each week of pregnancy and each month of childhood from birth until the end of follow-up (i.e. date of asthma diagnosis, end of follow-up or death). Residential location changes during pregnancy and during childhood were captured using health administrative data and ambient air pollution exposure was assigned by weighting the time spent at each location.

We assigned residential exposure to ambient UFPs derived from a land use regression (LUR) model developed using mobile monitoring data collected for two weeks in the summer (September 2010) and one week in the winter (March 2011) including data from 405 road segments distributed across the city of Toronto (34). In brief, the monitoring was conducted using 3 separate vehicles equipped with rooftop monitoring devices (TSI model 3007; TSI Inc., 
Shoreview, Minnesota) measuring real-time ambient UFPs at 1-second resolution. The terms in the LUR model include the logarithm of distances to highways, major roads, the central business district, Toronto Pearson International Airport, and bus routes. The LUR model also includes variables for the numbers of on-street trees, parks and open spaces, the length of bus routes within a 100-m buffer, as well as linear and quadratic terms for ambient temperature which were found to be important determinants of temporal variations in ambient UFPs (34-37). The final model explained $67 \%$ of the variation in mean UFPs. Therefore, this model allowed us to estimate both spatial and temporal variations in outdoor UFP concentrations. Specifically, we assigned exposures during each week of pregnancy and for each month of childhood by incorporating daily average ambient temperature surfaces in our UFPs LUR model at the 6-digit postal code resolution for the city of Toronto. The surfaces were provided by the Canadian Urban Environmental Health Research Consortium (CANUE) and were developed by the Canadian Forest Service of Natural Resources Canada $(38,39)$.

Weekly $\mathrm{PM}_{2.5}$ concentrations during pregnancy and monthly $\mathrm{PM}_{2.5}$ concentrations during childhood were derived from satellite surfaces available at a $1 \times 1 \mathrm{~km}$ resolution. Satellite surfaces were obtained based on van Donkelaar et al. (2015) that used $1 \times 1 \mathrm{~km}$ optimal estimation (OE) aerosol optical depth (AOD) which was related to $\mathrm{PM}_{2.5}$ with a chemical transport model and accounted for regional bias by applying a geographically weighted regression (GWR) using ground monitors for $\mathrm{PM}_{2.5}(40,41)$. Exposure to ambient $\mathrm{NO}_{2}$ was based on a LUR model derived from a monitoring campaign of ground-level concentrations of $\mathrm{NO}_{2}$ conducted in the City of Toronto (42).

We applied a temporal adjustment to the satellite-derived $\mathrm{PM}_{2.5}$ estimates and $\mathrm{LUR} \mathrm{NO}_{2}$ model in order to more precisely identify exposures on a weekly basis during pregnancy and 
monthly basis during childhood (18). A ratio was calculated based on weekly mean $\mathrm{PM}_{2.5}$ and $\mathrm{NO}_{2}$ concentrations at each ground monitor location in the City of Toronto to the long term satellite-derived and LUR model estimated concentrations for each of these monitor locations. The ambient concentrations of $\mathrm{PM}_{2.5}$ and $\mathrm{NO}_{2}$ at each fixed-site monitor locations were obtained from Environment Canada. Scaling surfaces were then created for each week of the study period by applying inverse distance weighting (IDW) spatial interpolation methods for each postal code located within $25 \mathrm{~km}$ of a ground monitor. The weekly $\mathrm{PM}_{2.5}$ and $\mathrm{NO}_{2}$ surface concentrations were obtained by applying the scaling surfaces to the long-term estimates (43). Weekly surfaces were then used to estimate exposures during pregnancy averaged up and assigned on a monthly basis for each month after birth in order to obtain childhood exposures.

\section{Covariates}

We used information available from health administrative databases to extract the following individual-level covariates, based on prior literature $(10,12,18)$ : birth weight, infant sex, gestational age (in weeks), maternal age at delivery ( $<20,20-34, \geq 35$ or missing), maternal cigarette smoking anytime during pregnancy (yes, no or missing), parity $(0,1, \geq 2)$, maternal breastfeeding intentions on discharge (yes, no or missing), maternal history of asthma (33) and season of birth ((winter (January to March), spring (April to June), summer (July to September) and fall (October to December)). Since we did not have individual-level socioeconomic status (SES) information, we captured SES variables from the 2006 Canadian census dissemination area (DA) data (i.e. median family income in the DA, proportion of visible minority in the DA, and percentage of female aged 25-64 years who completed postsecondary education in the DA). 
Finally, we obtained estimates of exposure to green space at the residential location during pregnancy using the Normalized Difference Vegetation Index (NDVI). The NDVI is derived from satellite data and characterizes the coverage and density of green vegetation (44). Since the greenness measures were available as annual averages for each postal code, we calculated the weighted average of exposure during pregnancy using consecutive years. The NDVI has been used in prior epidemiological studies focusing in the pregnancy period $(18,45)$.

\section{Statistical analysis}

The associations between exposure to ambient air pollution and incidence of childhood asthma were evaluated with random-effects Cox proportional hazards models. We assigned random-effects by neighborhoods $(n=140)$ and we assumed that any two neighborhoods were independent $(46,47)$. We also used random effects in order to account for clustering within families (i.e. accounting for births to the same mother) (48). Follow-up time was measured as each children's age in months from birth until any of the following: diagnosis of childhood asthma, death, becoming ineligible for provincial health insurance, movement out of Toronto, or end of follow-up. We created risk sets based on failure times (i.e. age in months) of cohort participants. Distributed lag non-linear models (DLNMs) were used to evaluate associations between ambient air pollution and childhood asthma incidence. The use of DLNMs allowed the simultaneous estimation of exposure-response associations and nonlinear effects across the lag-response associations (i.e. weekly exposures during pregnancy and monthly exposures during childhood) (49). Recent studies have used DLNMs in the context of air pollution and birth outcomes in order to identify sensitive windows of exposure and simultaneously account for potential confounding 
by other time periods of exposure $(50,51)$. For each pollutant, DLNMs were defined through two "cross-basis" matrices, one for exposures during gestational weeks 1 to 40 and one for childhood exposures from the first month after birth until the end of follow-up. For childhood exposures, we created cross-basis matrices of exposure for each person-time observation (i.e. time varying exposure from birth until each month of follow-up during childhood). Lag-response associations were modeled using natural cubic splines with 4 degrees of freedom for exposure during pregnancy and using a constant-risk model during childhood. The number of degrees of freedom and models were chosen based on the Akaike information criterion (AIC) (52). The exposure-response functions were assumed to be linear, but exposure-response curves, allowing non-linearity, were evaluated for statistically significant findings in sensitivity analyses. Separate analyses were conducted for the cumulative effect estimates during the 3 trimesters of pregnancy (i.e. weeks 113, weeks 14-26, and weeks 27-40), the overall pregnancy (i.e. from time of conception until delivery) and for overall childhood (i.e. from birth until date of asthma diagnosis, end of followup or death). All models investigating the cumulative effect over each trimester and the overall pregnancy were adjusted for childhood exposures. Similarly, models investigating the cumulative effect of childhood exposures were adjusted for pregnancy exposures. After investigating the cross product of each variable with the natural logarithm of the time variable, we did not find any violations of the proportional hazards assumption ( $>>0.05)$. We presented findings using the hazard ratio (HR) and 95\% confidence interval (CI) which corresponded to increases across the interquartile ranges (IQR) of UFPs, $\mathrm{NO}_{2}$ and $\mathrm{PM}_{2.5}$.

Potential confounders were evaluated in the multivariable models using covariates previously mentioned using a backward deletion approach (53). We first adjusted for all potential confounders and then removed the covariate with the largest p-value one by one in a stepwise 
manner as long as the total proportional change in the hazard ratio compared with the fully adjusted model was less than $10 \%$. Covariates that were not found to be confounders, but increased the precision of the hazard ratio were kept in the final model. We also made use of a directed acyclic graph (DAG), built using DAGitty version 2.3, to ensure proper adjustment for potential confounders. Using the DAG presented in supplementary Figure E2 and the DAG theory, we identified the minimal sufficient adjustment set of variables for estimating the direct effect of ambient air pollution exposure on development of childhood asthma. In all models, missing values for covariates were categorized as "missing" or "unknown" so that all observations were retained in the models. For example, maternal cigarette smoking status during pregnancy was categorized as "yes", "no" or "missing”, for those with missing or unknown values for this variable. We also assessed potential effect modification by stratifying by maternal history of asthma status, whether pregnant women smoked during pregnancy, birth weight, gestational age and infant sex. The significance of effect modification was evaluated by specifying cross product interaction terms between each pollutant (i.e. UFPs, $\mathrm{PM}_{2.5}$ and $\mathrm{NO}_{2}$ ) and each potential effect modifier. We used Wald's method to assess the statistical significance of interaction terms (i.e. p-value for interaction less than 0.05 ).

Several sensitivity analyses were conducted. We stratified analyses by the child's age at diagnosis (<1 year vs. $1-5$ years of age), restricted our analyses according to mothers who did not change residence during the course of their pregnancy, restricted our analyses to those with maternal information on pre-pregnancy body mass index, restricted to term births weighting over 2500 grams, and examined two- and three-pollutant models. All analyses were conducted with R (version 3.1.4), using the "coxme" and "dlnm" packages. Ethics approval for this study was 
granted by the Research Ethics Boards of Health Canada and the Ottawa Health Science Network

\section{Results}

In total, 160,641 singleton live births occurred between April $1^{\text {st }} 2006$ and March $31^{\text {st }}$ 2012 (Table 1). Before age 6, 27,062 children were diagnosed with asthma. Asthmatic children had a significantly smaller birth weight (3276.4 \pm 588.3 vs. $3321.8 \pm 530.4$ grams), a shorter gestational length $(38.6+/-2.1$ vs. $38.9+/-1.9$ weeks $)$, were more often born to mothers with a history of asthma (7.6\% vs. $4.4 \%)$ and mothers who smoked during pregnancy (4.7\% vs. $4.3 \%$ ) (p-values <0.001). The average age at which children were diagnosed with asthma was 2.1 years. We found that 7,960 mothers had a previous diagnosis of asthma and 26,692 mothers had multiple pregnancies.

The mean concentration of exposure to UFPs during the whole pregnancy period was 28,910 count $/ \mathrm{cm}^{3}$ (Table 2). Average exposures and IQRs for UFPs were similar across the different trimesters. Exposure to UFPs during the whole pregnancy period were not correlated with $\mathrm{PM}_{2.5}$ (Pearson correlation coefficient, $\left.r=0.04\right)$ or $\mathrm{NO}_{2}(r=0.01)$ (Supplementary Table E1). No correlations were observed between UFPs and the other two pollutants during each trimester of pregnancy and during childhood years $(r<0.05)$ (results not shown). In fact, weak or no correlations have also been found in previous studies evaluating health effects of UFPs in Montreal and Toronto in Canada $(47,54)$. We found moderate correlations between $\mathrm{PM}_{2.5}$ and $\mathrm{NO}_{2}$ during the full pregnancy period $(\mathrm{r}=0.41)$ (Supplementary Table E1). The IQRs for UFPs, 
$\mathrm{PM}_{2.5}$ and $\mathrm{NO}_{2}$ over the whole pregnancy period were $10,820 \mathrm{count} / \mathrm{cm}^{3}, 3.8 \mu \mathrm{g} / \mathrm{m}^{3}$ and $9.7 \mathrm{ppb}$, respectively (Table 3).

The associations between each pollutant (i.e. UFPs, $\mathrm{PM}_{2.5}$ and $\mathrm{NO}_{2}$ ) and childhood asthma incidence are presented in Table 3. All models were mutually adjusted for the distributed lag weekly exposures of the selected pollutant during the pregnancy period, distributed lag monthly childhood exposures to the selected pollutant, maternal age at birth, infant sex, parity, breastfeeding status, maternal smoking status during pregnancy, maternal atopy, gestational age, birth weight, residential green space exposure during pregnancy, three neighbourhood-level socioeconomic status (SES) variables, a frailty term for neighbourhood in the city of Toronto, and random effects for clustering within families. UFP concentrations during the second trimester were positively associated with childhood asthma incidence [HR $=1.09 ; 95 \% \mathrm{CI}: 1.06$, 1.12 for a 10,770 count $/ \mathrm{cm}^{3}$ (IQR) increase], while associations for other time periods were close to the null and not statistically significant. We also found a linear association between UFPs during the second trimester and childhood asthma incidence when conducting an exposureresponse analysis (Figure 1). Hazard ratios for exposures to $\mathrm{PM}_{2.5}[\mathrm{HR}=1.08 ; 95 \% \mathrm{CI}$ : 1.05 , 1.11 for a $3.8 \mu \mathrm{g} / \mathrm{m}^{3}$ (IQR) increase $]$ and $\mathrm{NO}_{2}[\mathrm{HR}=1.12 ; 95 \% \mathrm{CI}: 1.09,1.15$ for a $9.7 \mathrm{ppb}$ (IQR) increase] during the second trimester were also statistically significant. Exposure-response curves for associations between $\mathrm{PM}_{2.5}$ and $\mathrm{NO}_{2}$ and childhood asthma incidence are reported in supplementary Figure E1. In the multi-pollutant models adjusted for $\mathrm{PM}_{2.5}$ and $\mathrm{NO}_{2}$, exposure to UFPs during the second trimester remained positively associated with childhood asthma incidence (HR: 1.05; 95\%CI: 1.01-1.09) (Table 4). The independent effect of $\mathrm{PM}_{2.5}$ and $\mathrm{NO}_{2}$ remained statistically significant after adjustment for the other pollutants (Supplemental Tables 
E2 \& E3). In the stratified analyses, we did not observe statistically significant effect modification by the selected characteristics (Supplementary Table E4).

In the sensitivity analyses, the stratification of hazard ratios by the child's age at diagnosis of asthma (<1 year vs. 1-5 years of age) did not reveal any significant differences (results not shown). However, the hazard ratios limited to children $<1$ year were not statistically significant. In addition, restricting our analyses to mothers who did not move residences during pregnancy did not materially alter the results (results not shown). Additional adjustment for maternal prepregnancy body mass index (BMI) in a subset of our cohort (i.e. about $20 \%$ of our cohort had BMI information) did not change the hazard ratios (results not shown). Finally, hazard ratios were materially unchanged when we restricted our analyses to term births over 2500 grams (Supplemental Table E5).

\section{Discussion}

A small number of studies have reported respiratory health effects in children following short-term exposure to UFPs (20-26). In this study, we evaluated associations between gestational and early life exposures to UFPs and childhood asthma incidence. Our findings suggest that exposure to UFPs during the second trimester increases risk of asthma incidence in children up to age 6 . These findings remained positive after adjustment for $\mathrm{PM}_{2.5}$ and $\mathrm{NO}_{2}$ in multi-pollutant models.

Several epidemiological studies have reported positive associations between exposure to air pollution and incidence of childhood asthma (4-18). Among those studies, some reported associations between exposure to air pollution, in particular $\mathrm{PM}_{2.5}$ and to a lesser extent $\mathrm{NO}_{2}$, 
during the prenatal period and asthma onset in children $(10,14,15)$. Despite the documented effects of particulate air pollution on childhood asthma incidence and concerns that UFPs might be more toxic than the larger particulate matter, the effects of UFPs on asthma onset in children are not well studied. Previous research has primarily focused on the short-term effects of UFPs on respiratory health in children with studies reporting associations between UFPs and wheezing symptoms $(21,22)$, current asthma (26), spirometry and exhaled nitric oxide measurements (23) and health care utilization-related visits for respiratory outcomes (25). A recent cross-sectional study conducted among 655 children aged 8 to 11 years in the Brisbane Metropolitan Area, Australia, found that annual average exposure to UFP was associated with systemic inflammation, as measured by serum C-reactive protein (CRP). In addition, UFP exposure was associated with airway inflammation in atopic children (27).

The vulnerable weeks of exposure to air pollution identified in this study correspond to important phases (i.e. late pseudoglandular and canicular phases) of lung development during the fetal period (55). In fact, a number of important functions and tissues are developing during those phases including the development of airways, airway epithelium differentiation and immune modulators secretion (28). The immune and respiratory systems of the developing fetus may be affected by increases in inflammation and increased sensitivity of the airways following exposure to ambient air pollution (56), enhancing susceptibility to asthma (10, 28-30). Indeed, our findings suggesting an association between UFP exposures during the second trimester of pregnancy and childhood asthma incidence are generally in agreement with prior studies on other air pollutants including $\mathrm{PM}_{2.5}$ and $\mathrm{NO}_{2}$. Specifically, we previously reported that exposures to $\mathrm{PM}_{2.5}$ and $\mathrm{NO}_{2}$ during the second trimester of pregnancy were associated with childhood asthma incidence (18). In a study conducted in Boston, Massachusetts, authors found that exposure to 
$\mathrm{PM}_{2.5}$ during pregnancy was associated with asthma incidence in children by age 6 years only during weeks corresponding to the second trimester of pregnancy $(10,15)$. In addition, results based on 2,598 children enrolled in a study in China found that second trimester exposure to $\mathrm{NO}_{2}$ was associated with asthma incidence $(\mathrm{OR}=1.72,95 \% \mathrm{CI}$ : $1.02,2.97)(14)$. Morales et al. also showed that exposure to $\mathrm{NO}_{2}$ during the second trimester was associated with a reduction in lung functions measured at 4.5 years of age (4). Therefore, our findings related to second trimester exposure to UFPs and childhood asthma incidence are generally consistent with prior literature and corresponds to an important time-period for the developing respiratory system.

Several limitations of this analysis should be noted. First, our UFPs and $\mathrm{NO}_{2}$ exposures estimates for the time period were assigned using LUR models based on data collected from short-term monitoring campaigns using a temporal scaling adjustment in order to capture different periods of exposure. We were therefore unable to obtain spatial-temporal ground estimates measured across the City of Toronto due to technological challenges and high costs. However, we applied previously published methods in order to capture as accurately as possible temporal changes in UFPs and $\mathrm{NO}_{2}(34,43)$. Secondly, we need to acknowledge that there may be potential residual confounding. For instance, no individual-level information was available for income, education, ethnicity and maternal stress levels. While we were able to conduct a sensitivity analysis using pre-pregnancy body mass index information in a subset of our population, we did not have information on maternal gestational weight gain, an important risk factor for childhood asthma development (57). However, controlling for some neighbourhoodlevel SES factors may have partially accounted for these missing variables. In addition, we did not have information on asthma phenotypes, asthma severity in children and medications to treat or control asthma during the pregnancy period. 
To our knowledge, this is the first study to examine the effects of prenatal and early postnatal exposure to UFPs on childhood asthma incidence. Some of the strengths of this study include the air pollution exposure estimates that captured both spatial and temporal variation, the large sample size and the residential mobility information during pregnancy. We also identified incident cases using province-wide registries and validated algorithms with high sensitivity and specificity. The risk of selection bias was likely reduced due to the population-based approach we used.

In this large population-based study, we found that exposure to UFPs during the second trimester of pregnancy was associated with an increased risk of developing asthma in children before age 6 independent of other air pollutants including $\mathrm{NO}_{2}$ and $\mathrm{PM}_{2.5}$. These findings reinforce the importance of conduction further research on the effects of UFPs during the perinatal period on respiratory health in children. 


\section{Acknowledgements}

This study was supported by the Institute for Clinical Evaluative Sciences (ICES), which is funded by an annual grant from the Ontario Ministry of Health and Long-Term Care

(MOHLTC). The opinions, results and conclusions reported in this paper are those of the authors and are independent from the funding sources. No endorsement by ICES or the Ontario MOHLTC is intended or should be inferred. "Parts of this material are based on data and/or information compiled and provided by the Canadian Institute for Health Information (CIHI). However, the analyses, conclusions, opinions and statements expressed in the material are those of the author(s), and not necessarily those of CIHI." This Study is based in part on data provided by Better Outcomes Registry and Network (“BORN”), part of the Children's Hospital of Eastern Ontario. The interpretation and conclusions contained herein do not necessarily represent those of BORN Ontario. Weather-related indicators, indexed to DMTI Spatial Inc. postal codes, were calculated and provided by CANUE (Canadian Urban Environmental Health Research Consortium). Weather-related base data (daily mean temperature) were provided by the Canadian Forest Service, Natural Resources Canada. 


\section{References}

(1) Asher I, Dagli E. Environmental influences on asthma and allergy. Chem Immunol Allergy 2004;84:36-101.

(2) Milligan KL, Matsui E, Sharma H. Asthma in Urban Children: Epidemiology, Environmental Risk Factors, and the Public Health Domain. Curr Allergy Asthma Rep 2016;16:33-016-0609-6.

(3) Ferrante G, La Grutta S. The Burden of Pediatric Asthma. Frontiers in pediatrics 2018;6:186; 186-186.

(4) Morales E, Garcia-Esteban R, de la Cruz OA, Basterrechea M, Lertxundi A, de Dicastillo $\mathrm{MD}$, Zabaleta C, Sunyer J. Intrauterine and early postnatal exposure to outdoor air pollution and lung function at preschool age. Thorax 2015;70:64-73.

(5) Mortimer K, Neugebauer R, Lurmann F, Alcorn S, Balmes J, Tager I. Air pollution and pulmonary function in asthmatic children: effects of prenatal and lifetime exposures. Epidemiology 2008;19:550-7; discussion 561-2.

(6) Schultz ES, Litonjua AA, Melen E. Effects of Long-Term Exposure to Traffic-Related Air Pollution on Lung Function in Children. Curr Allergy Asthma Rep 2017;17:41-017-0709-y. (7) Schultz ES, Hallberg J, Bellander T, Bergstrom A, Bottai M, Chiesa F, Gustafsson PM, Gruzieva O, Thunqvist P, Pershagen G, Melen E. Early-Life Exposure to Traffic-related Air Pollution and Lung Function in Adolescence. Am J Respir Crit Care Med 2016;193:171-177. (8) Khreis H, Kelly C, Tate J, Parslow R, Lucas K, Nieuwenhuijsen M. Exposure to trafficrelated air pollution and risk of development of childhood asthma: A systematic review and meta-analysis. Environ Int 2016.

(9) Gasana J, Dillikar D, Mendy A, Forno E, Ramos Vieira E. Motor vehicle air pollution and asthma in children: a meta-analysis. Environ Res 2012;117:36-45.

(10) Hsu HH, Chiu YH, Coull BA, Kloog I, Schwartz J, Lee A, Wright RO, Wright RJ. Prenatal Particulate Air Pollution and Asthma Onset in Urban Children. Identifying Sensitive Windows and Sex Differences. Am J Respir Crit Care Med 2015;192:1052-1059.

(11) Clark NA, Demers PA, Karr CJ, Koehoorn M, Lencar C, Tamburic L, Brauer M. Effect of early life exposure to air pollution on development of childhood asthma. Environ Health Perspect 2010;118:284-290.

(12) Sbihi H, Tamburic L, Koehoorn M, Brauer M. Perinatal air pollution exposure and development of asthma from birth to age 10 years. Eur Respir J 2016;47:1062-1071. (13) Deng Q, Lu C, Norback D, Bornehag CG, Zhang Y, Liu W, Yuan H, Sundell J. Early life exposure to ambient air pollution and childhood asthma in China. Environ Res 2015;143:83-92. (14) Deng Q, Lu C, Li Y, Sundell J, Dan N. Exposure to outdoor air pollution during trimesters of pregnancy and childhood asthma, allergic rhinitis, and eczema. Environ Res 2016;150:119127.

(15) Lee A, Leon Hsu HH, Mathilda Chiu YH, Bose S, Rosa MJ, Kloog I, Wilson A, Schwartz J, Cohen S, Coull BA, Wright RO, Wright RJ. Prenatal fine particulate exposure and early childhood asthma: Effect of maternal stress and fetal sex. J Allergy Clin Immunol 2018;141:1880-1886.

(16) Liu W, Huang C, Hu Y, Fu Q, Zou Z, Sun C, Shen L, Wang X, Cai J, Pan J, Huang Y, Chang J, Sun Y, Sundell J. Associations of gestational and early life exposures to ambient air pollution with childhood respiratory diseases in Shanghai, China: A retrospective cohort study. Environment International 2016;92:284-293. 
(17) Hehua Z, Qing C, Shanyan G, Qijun W, Yuhong Z. The impact of prenatal exposure to air pollution on childhood wheezing and asthma: A systematic review. Environ Res 2017;159:519530.

(18) Lavigne E, Belair MA, Rodriguez Duque D, Do MT, Stieb DM, Hystad P, van Donkelaar A, Martin RV, Crouse DL, Crighton E, Chen H, Burnett RT, Weichenthal S, Villeneuve PJ, To T, Brook JR, Johnson M, Cakmak S, Yasseen AS,3rd, Walker M. Effect modification of perinatal exposure to air pollution and childhood asthma incidence. Eur Respir J 2018.

(19) HEI Review Panel on Ultrafine Particles. Understanding the health effects of Ambient Ultrafine Particles. : HEI Perspectives 3.; 2013.

(20) Heinzerling A, Hsu J, Yip F. Respiratory Health Effects of Ultrafine Particles in Children: A Literature Review. Water Air Soil Pollut 2016;227:10.1007/s11270-015-2726-6. Epub 2015 Dec 22.

(21) Andersen ZJ, Loft S, Ketzel M, Stage M, Scheike T, Hermansen MN, Bisgaard H. Ambient air pollution triggers wheezing symptoms in infants. Thorax 2008;63:710-716.

(22) Andersen ZJ, Wahlin P, Raaschou-Nielsen O, Ketzel M, Scheike T, Loft S. Size distribution and total number concentration of ultrafine and accumulation mode particles and hospital admissions in children and the elderly in Copenhagen, Denmark. Occup Environ Med 2008;65:458-466.

(23) Buonanno G, Marks GB, Morawska L. Health effects of daily airborne particle dose in children: direct association between personal dose and respiratory health effects. Environ Pollut 2013;180:246-250.

(24) Evans KA, Halterman JS, Hopke PK, Fagnano M, Rich DQ. Increased ultrafine particles and carbon monoxide concentrations are associated with asthma exacerbation among urban children. Environ Res 2014;129:11-19.

(25) Halonen JI, Lanki T, Yli-Tuomi T, Kulmala M, Tiittanen P, Pekkanen J. Urban air pollution, and asthma and COPD hospital emergency room visits. Thorax 2008;63:635-641.

(26) Kim JL, Elfman L, Wieslander G, Ferm M, Toren K, Norback D. Respiratory health among Korean pupils in relation to home, school and outdoor environment. J Korean Med Sci 2011;26:166-173.

(27) Clifford S, Mazaheri M, Salimi F, Ezz WN, Yeganeh B, Low-Choy S, Walker K, Mengersen K, Marks GB, Morawska L. Effects of exposure to ambient ultrafine particles on respiratory health and systemic inflammation in children. Environ Int 2018;114:167-180.

(28) Kato A, Favoreto S,Jr, Avila PC, Schleimer RP. TLR3- and Th2 cytokine-dependent production of thymic stromal lymphopoietin in human airway epithelial cells. J Immunol 2007;179:1080-1087.

(29) Moffatt MF, Gut IG, Demenais F, Strachan DP, Bouzigon E, Heath S, von Mutius E, Farrall M, Lathrop M, Cookson WO, GABRIEL Consortium. A large-scale, consortium-based genomewide association study of asthma. N Engl J Med 2010;363:1211-1221.

(30) Nadeau K, McDonald-Hyman C, Noth EM, Pratt B, Hammond SK, Balmes J, Tager I. Ambient air pollution impairs regulatory T-cell function in asthma. J Allergy Clin Immunol 2010;126:845-852.e10.

(31) Dunn S, Bottomley J, Ali A, Walker M. 2008 Niday Perinatal Database quality audit: report of a quality assurance project. Chronic Dis Inj Can 2011;32:32-42.

(32) To T, Dell S, Dick PT, Cicutto L, Harris JK, MacLusky IB, Tassoudji M. Case verification of children with asthma in Ontario. Pediatr Allergy Immunol 2006;17:69-76. 
(33) Gershon AS, Wang C, Guan J, Vasilevska-Ristovska J, Cicutto L, To T. Identifying patients with physician-diagnosed asthma in health administrative databases. Can Respir J 2009;16:183188.

(34) Weichenthal S, Van Ryswyk K, Goldstein A, Shekarrizfard M, Hatzopoulou M.

Characterizing the spatial distribution of ambient ultrafine particles in Toronto, Canada: A land use regression model. Environ Pollut 2016;208:241-248.

(35) Weichenthal S, Ryswyk KV, Goldstein A, Bagg S, Shekkarizfard M, Hatzopoulou M. A land use regression model for ambient ultrafine particles in Montreal, Canada: A comparison of linear regression and a machine learning approach. Environ Res 2016;146:65-72.

(36) Kaur S, Nieuwenhuijsen MJ. Determinants of personal exposure to PM2.5, ultrafine particle counts, and CO in a transport microenvironment. Environ Sci Technol 2009;43:4737-4743.

(37) Alm S, Jantunen MJ, Vartiainen M. Urban commuter exposure to particle matter and carbon monoxide inside an automobile. J Expo Anal Environ Epidemiol 1999;9:237-244.

(38) Canadian Forest Service of Natural Resources Canada. Customized spatial climate data files prepared for the Canadian Urban Environmental Health Research Consortium by the Canadian Forest Service of Natural Resources Canada. October 2017.

(39) DMTI Spatial Inc. CanMap Postal Code Suite v2015.3. 2015.

(40) van Donkelaar A, Martin RV, Spurr RJ, Burnett RT. High-Resolution Satellite-Derived PM2.5 from Optimal Estimation and Geographically Weighted Regression over North America. Environ Sci Technol 2015;49:10482-10491.

(41) Brunsdon C, Fotheringham AS, Charlton ME. Geographically Weighted Regression: A Method for Exploring Spatial Nonstationarity. Geogr Anal 1996;28:281-298.

(42) Jerrett M, Arain MA, Kanaroglou P, Beckerman B, Crouse D, Gilbert NL, Brook JR, Finkelstein N, Finkelstein MM. Modeling the intraurban variability of ambient traffic pollution in Toronto, Canada. J Toxicol Environ Health A 2007;70:200-212.

(43) Bechle MJ, Millet DB, Marshall JD. National Spatiotemporal Exposure Surface for NO2: Monthly Scaling of a Satellite-Derived Land-Use Regression, 2000-2010. Environ Sci Technol 2015;49:12297-12305.

(44) Rhew IC, Vander Stoep A, Kearney A, Smith NL, Dunbar MD. Validation of the normalized difference vegetation index as a measure of neighborhood greenness. Ann Epidemiol 2011;21:946-952.

(45) Hystad P, Davies HW, Frank L, Van Loon J, Gehring U, Tamburic L, Brauer M. Residential greenness and birth outcomes: evaluating the influence of spatially correlated built-environment factors. Environ Health Perspect 2014;122:1095-1102.

(46) Bai L, Chen H, Hatzopoulou M, Jerrett M, Kwong JC, Burnett RT, van Donkelaar A, Copes R, Martin RV, Van Ryswyk K, Lu H, Kopp A, Weichenthal S. Exposure to Ambient Ultrafine Particles and Nitrogen Dioxide and Incident Hypertension and Diabetes. Epidemiology 2018;29:323-332.

(47) Weichenthal S, Bai L, Hatzopoulou M, Van Ryswyk K, Kwong JC, Jerrett M, van Donkelaar A, Martin RV, Burnett RT, Lu H, Chen H. Long-term exposure to ambient ultrafine particles and respiratory disease incidence in in Toronto, Canada: a cohort study. Environ Health 2017;16:64-017-0276-7.

(48) Lavigne E, Belair MA, Do MT, Stieb DM, Hystad P, van Donkelaar A, Martin RV, Crouse DL, Crighton E, Chen H, Brook JR, Burnett RT, Weichenthal S, Villeneuve PJ, To T, Cakmak S, Johnson M, Yasseen AS,3rd, Johnson KC, Ofner M, Xie L, Walker M. Maternal exposure to 
ambient air pollution and risk of early childhood cancers: A population-based study in Ontario, Canada. Environ Int 2017;100:139-147.

(49) Gasparrini A. Modeling exposure-lag-response associations with distributed lag non-linear models. Stat Med 2014;33:881-899.

(50) Martens DS, Cox B, Janssen BG, Clemente DBP, Gasparrini A, Vanpoucke C, Lefebvre W, Roels HA, Plusquin M, Nawrot TS. Prenatal Air Pollution and Newborns' Predisposition to Accelerated Biological Aging. JAMA Pediatr 2017;171:1160-1167.

(51) Wilson A, Chiu YM, Hsu HL, Wright RO, Wright RJ, Coull BA. Potential for Bias When Estimating Critical Windows for Air Pollution in Children's Health. Am J Epidemiol 2017;186:1281-1289.

(52) Gasparrini A, Armstrong B, Kenward MG. Distributed lag non-linear models. Stat Med 2010;29:2224-2234.

(53) Rothman KJ, Greenland S, Lash TL. Modern epidemiology. Philadelphia: Lippincott, Williams \& Wilkins; 2008.

(54) Weichenthal S, Hatzopoulou M, Goldberg MS. Exposure to traffic-related air pollution during physical activity and acute changes in blood pressure, autonomic and micro-vascular function in women: a cross-over study. Part Fibre Toxicol 2014;11:70-014-0070-4.

(55) Schittny JC. Development of the lung. Cell Tissue Res 2016;367:427-444.

(56) Burri PH. Fetal and postnatal development of the lung. Annu Rev Physiol 1984;46:617-628.

(57) Forno E, Young OM, Kumar R, Simhan H, Celedon JC. Maternal obesity in pregnancy, gestational weight gain, and risk of childhood asthma. Pediatrics 2014;134:e535-46. 


\section{Figure legend}

Figure 1. Exposure-response curve using natural cubic splines with 3 degrees of freedom for the association between exposure to UFPs during the second trimester of pregnancy and childhood asthma incidence in Ontario, Canada (2006 - 2012). Middle line reflects point estimates and upper and lower lines reflect $95 \%$ confidence intervals. The reference concentration by which the hazard ratios are computed is $29000 \mathrm{~cm}^{3}$ (approximately median value). Model mutually adjusted for the distributed lag weekly exposures of the selected pollutant during the pregnancy period, distributed lag monthly exposures after birth to the selected pollutant, maternal age at delivery, infant sex, parity, breastfeeding status at the time of discharge, maternal smoking during pregnancy, maternal atopy, gestational age, birth weight, residential greenness exposure during pregnancy, dissemination area median family income, dissemination area proportion of population who are visible minority, dissemination area proportion of the adult female population aged 25-64 years old who completed postsecondary education, a frailty term for neighbourhood in the city of Toronto and random effects for clustering within families.. 
Table 1. Demographic and socioeconomic characteristics of study participants ${ }^{\mathrm{a}}$.

\begin{tabular}{|c|c|c|c|}
\hline Characteristics & Total cohort & Asthmatic children & Non-asthmatic children \\
\hline $\bar{n}$ & 160,641 & 27,062 & 133,579 \\
\hline Maternal age & $30.0(5.5)$ & $30.1(5.53)$ & $30.0(5.5)$ \\
\hline Gestational length (weeks) & $38.8(1.8)$ & $38.6(2.1)$ & $38.9(1.8)$ \\
\hline Birth weight (grams) & $3314.1(540.9)$ & $3276.4(588.3)$ & $3321.8(530.4)$ \\
\hline \multicolumn{4}{|l|}{ Infant sex } \\
\hline Male & $82,709(51.5)$ & $16,434(60.7)$ & $66,275(49.6)$ \\
\hline Female & $77,932(48.5)$ & $10,628(39.3)$ & 67,304 (50.4) \\
\hline \multicolumn{4}{|l|}{ Parity } \\
\hline 0 & $92,252(57.4)$ & $14,811(54.7)$ & $77,441(58.0)$ \\
\hline 1 & $48,679(30.3)$ & $8,602(31.8)$ & $40,077(30.0)$ \\
\hline$\geq 2$ & $19,710(12.3)$ & 3,649 (13.5) & $16,061(12.0)$ \\
\hline \multicolumn{4}{|l|}{ Intention to breastfeed } \\
\hline Yes & $133,006(82.8)$ & $21,946(81.1)$ & $111,060(83.1)$ \\
\hline No & $7,991(5.0)$ & $1,429(5.3)$ & $6,562(4.9)$ \\
\hline Missing & $19,644(12.2)$ & 3,687 (13.6) & 15,957 (11.9) \\
\hline \multicolumn{4}{|c|}{ Maternal smoking status during pregnancy } \\
\hline Yes & $6,961(4.3)$ & $1,270(4.7)$ & $5,691(4.3)$ \\
\hline No & $137,365(85.5)$ & $22,740(84.0)$ & $114,625(85.8)$ \\
\hline Missing & $16,315(10.2)$ & $3,052(11.3)$ & $13,263(9.9)$ \\
\hline \multicolumn{4}{|l|}{ Maternal asthma } \\
\hline Yes & $7,960(5.0)$ & $2,065(7.6)$ & $5,895(4.4)$ \\
\hline No & $152,681(95.0)$ & 24,997 (92.4) & $127,684(95.6)$ \\
\hline \multicolumn{4}{|l|}{ Median family income } \\
\hline Quintile 1 & $31,879(19.8)$ & $5,726(21.2)$ & 26,153 (19.6) \\
\hline Quintile 2 & $31,897(19.9)$ & $5,575(20.6)$ & $26,322(19.7)$ \\
\hline Quintile 3 & $31,927(19.9)$ & $5,332(19.7)$ & 26,595 (19.9) \\
\hline Quintile 4 & $31,926(19.9)$ & $4,609(17.0)$ & $27,317(20.5)$ \\
\hline Quintile 5 & $984(0.6)$ & $117(0.4)$ & $867(0.6)$ \\
\hline Missing & $31,879(19.8)$ & $5,726(21.2)$ & $26,153(19.6)$ \\
\hline \multicolumn{4}{|c|}{ Percent of females completed postsecondary education (age $25+$ ) } \\
\hline Quintile 1 & $22,856(19.5)$ & $5,085(21.8)$ & 27,941 (19.9) \\
\hline Quintile 2 & $22,798(19.5)$ & $5,048(21.6)$ & $27,846(19.8)$ \\
\hline Quintile 3 & $23,458(20.1)$ & 4,645 (19.9) & $28,103(20.0)$ \\
\hline Quintile 4 & $23,161(19.8)$ & 4,492 (19.2) & $27,653(19.7 \%)$ \\
\hline Quintile 5 & $23,914(20.4)$ & $3,970(17.0)$ & $27,884(19.9 \%)$ \\
\hline Missing & $776(0.7)$ & $102(0.4)$ & $878(0.6 \%)$ \\
\hline \multicolumn{4}{|l|}{ Percent visible minority } \\
\hline Quintile 1 & $27,103(20.3)$ & $4,780(17.7)$ & $31,883(19.8)$ \\
\hline Quintile 2 & $26,944(20.2)$ & $4,996(18.5)$ & $31,940(19.9)$ \\
\hline Quintile 3 & $26,430(19.8)$ & $5,454(20.2)$ & $31,884(19.8)$ \\
\hline Quintile 4 & $26,385(19.8)$ & $5,561(20.5)$ & $31,946(19.9)$ \\
\hline Quintile 5 & $25,788(19.3)$ & $6,139(22.7)$ & $31,927(19.9)$ \\
\hline Missing & $929(0.7)$ & $132(0.5)$ & $1,061(0.7)$ \\
\hline
\end{tabular}

n (\%) for categorical covariates; mean (standard deviation) for continuous covariates. 
Table 2. Descriptive statistics of UFPs and Pearson correlation coefficients across time periods.

UFP (count/ $/ \mathrm{cm}^{3}$ )

\begin{tabular}{|c|c|c|c|c|c|c|c|c|}
\hline & \multirow[b]{2}{*}{ Mean } & \multirow[b]{2}{*}{ SD } & \multirow[b]{2}{*}{ IQR } & \\
\hline & & & & $\begin{array}{c}1 \mathrm{st} \\
\text { trimester }\end{array}$ & $\begin{array}{c}\text { 2nd } \\
\text { trimester }\end{array}$ & $\begin{array}{c}\text { 3rd } \\
\text { trimester }\end{array}$ & Pregnancy average & Childhood cumulative exposure \\
\hline \multicolumn{9}{|l|}{ UFP $\left(\right.$ count $\left./ \mathrm{cm}^{3}\right)$} \\
\hline $1^{\text {st }}$ trimester & 28,905 & 9,145 & 10,862 & 1.00 & & & & \\
\hline $2^{\text {nd }}$ trimester & 28,953 & 9,151 & 10,770 & 0.66 & 1.00 & & & \\
\hline $3^{\text {rd }}$ trimester & 28,870 & 9,154 & 10,853 & 0.62 & 0.63 & 1.00 & & \\
\hline Pregnancy average & 28,910 & 9,150 & 10,820 & 0.59 & 0.62 & 0.69 & 1.00 & \\
\hline Childhood cumulative exposure & 27,504 & 9,145 & 10,551 & 0.55 & 0.54 & 0.64 & 0.61 & 1.00 \\
\hline
\end{tabular}


Table 3. Hazard ratios (HR) and 95\% confidence intervals $(95 \% \mathrm{CI})$ for the associations between UFPs (per IQR), PM2.5 (per IQR) and $\mathrm{NO}_{2}$ (per IQR) over specific periods and childhood asthma risk.

\begin{tabular}{|c|c|c|c|c|c|c|}
\hline \multirow[b]{2}{*}{ Exposure period } & \multicolumn{2}{|c|}{$\overline{\text { UFPs }}$} & \multicolumn{2}{|c|}{$\mathrm{PM}_{2.5}$} & \multicolumn{2}{|c|}{$\mathrm{NO}_{2}$} \\
\hline & IQR $\left(\right.$ count $\left./ \mathrm{cm}^{3}\right)$ & $\begin{array}{c}\text { Adjusted model }^{\mathrm{a}} \\
\text { HR }(95 \% \mathrm{CI})\end{array}$ & IQR (in $\mu \mathrm{g} / \mathrm{m} 3$ ) & $\begin{array}{c}\text { Adjusted model }^{\mathrm{a}} \\
\text { HR }(95 \% \text { CI) }\end{array}$ & IQR (in ppb) & $\begin{array}{c}\text { Adjusted model }^{\mathrm{a}} \\
\text { HR }(95 \% \mathrm{CI})\end{array}$ \\
\hline $1^{\text {st }}$ trimester & 10,862 & $1.01(0.97-1.05)$ & 3.8 & $1.00(0.97-1.03)$ & 9.8 & $1.02(0.98-1.06)$ \\
\hline $2^{\text {nd }}$ trimester & 10,770 & $1.09(1.06-1.12)$ & 3.8 & $1.08(1.05-1.11)$ & 9.7 & $1.12(1.09-1.15)$ \\
\hline $3^{\text {rd }}$ trimester & 10,853 & $1.04(1.00-1.08)$ & 3.7 & $1.03(0.99-1.06)$ & 9.6 & $1.01(0.98-1.05)$ \\
\hline Entire pregnancy & 10,820 & $1.03(0.99-1.07)$ & 3.8 & $1.03(1.00-1.06)$ & 9.7 & $1.02(0.98-1.06)$ \\
\hline Childhood exposure & 10,551 & $1.03(1.00-1.06)$ & 3.4 & $1.02(0.99-1.05)$ & 8.7 & $1.01(0.97-1.05)$ \\
\hline
\end{tabular}

${ }^{a}$ Model mutually adjusted for the distributed lag weekly exposures of the selected pollutant during the pregnancy period, distributed lag monthly exposures after birth to the selected pollutant, maternal age at delivery, infant sex, parity, breastfeeding status at the time of discharge, maternal smoking during pregnancy, maternal atopy, gestational age, birth weight, residential greenness exposure during pregnancy, dissemination area median family income, dissemination area proportion of population who are visible minority, dissemination area proportion of the adult female population aged $25-64$ years old who completed postsecondary education, a frailty term for neighbourhood in the city of Toronto and random effects for clustering within families.

$\mathrm{IQR}$, interquartile range 
Table 4. Hazard ratios ${ }^{\mathrm{a}}(\mathrm{HR})$ and $95 \%$ confidence intervals $(95 \% \mathrm{CI})$ for the associations between UFPs (per IQR) over specific periods and childhood asthma risk with additional adjustment for $\mathrm{PM}_{2.5}$ and $\mathrm{NO}_{2}$.

\begin{tabular}{|c|c|c|c|c|}
\hline \multirow{2}{*}{ Exposure period } & \multirow{2}{*}{$\mathrm{IQR}\left(\right.$ count $\left./ \mathrm{cm}^{3}\right)$} & $\mathrm{UFPs}+\mathrm{PM}_{2.5}$ & $\mathrm{UFPs}+\mathrm{NO}_{2}$ & $\mathrm{UFPs}+\mathrm{PM}_{2.5}+\mathrm{NO}_{2}$ \\
\hline & & $\mathrm{HR}(95 \% \mathrm{CI})^{\mathrm{b}}$ & $\mathrm{HR}(95 \% \mathrm{CI})^{\mathrm{b}}$ & $\mathrm{HR}(95 \% \mathrm{CI})^{\mathrm{b}}$ \\
\hline $1^{\text {st }}$ trimester & 10,862 & $0.99(0.96-1.02)$ & $1.00(0.97-1.03)$ & $1.01(0.97-1.05)$ \\
\hline $2^{\text {nd }}$ trimester & 10,770 & $1.07(1.04-1.10)$ & $1.02(0.98-1.06)$ & $1.05(1.01-1.09)$ \\
\hline $3^{\text {rd }}$ trimester & 10,853 & $1.02(0.99-1.06)$ & $1.00(0.96-1.04)$ & $1.01(0.97-1.05)$ \\
\hline Entire pregnancy & 10,820 & $1.01(0.99-1.04)$ & $1.00(0.97-1.03)$ & $1.01(0.98-1.04)$ \\
\hline Childhood cumulative exposure & 10,551 & $1.01(0.97-1.04)$ & $0.99(0.96-1.02)$ & $1.00(0.97-1.04)$ \\
\hline
\end{tabular}

${ }^{a}$ Model mutually adjusted for the distributed lag weekly exposures of the selected pollutant during the pregnancy period, distributed lag monthly exposures after birth to the selected pollutant, maternal age at delivery, infant sex, parity, breastfeeding status at the time of discharge, maternal smoking during pregnancy, maternal atopy, gestational age, birth weight, residential greenness exposure during pregnancy, dissemination area median family income, dissemination area proportion of population who are visible minority, dissemination area proportion of the adult female population aged $25-64$ years old who completed postsecondary education, a frailty term for neighbourhood in the city of Toronto and random effects for clustering within families.

${ }^{b}$ Includes adjustment for the other pollutant(s) in the same exposure period.

IQR, interquartile range 
Figure 1. Exposure-response curve using natural cubic splines with 3 degrees of freedom for the association between exposure to UFPs during the second trimester of pregnancy and childhood asthma incidence in Ontario, Canada (2006 - 2012).

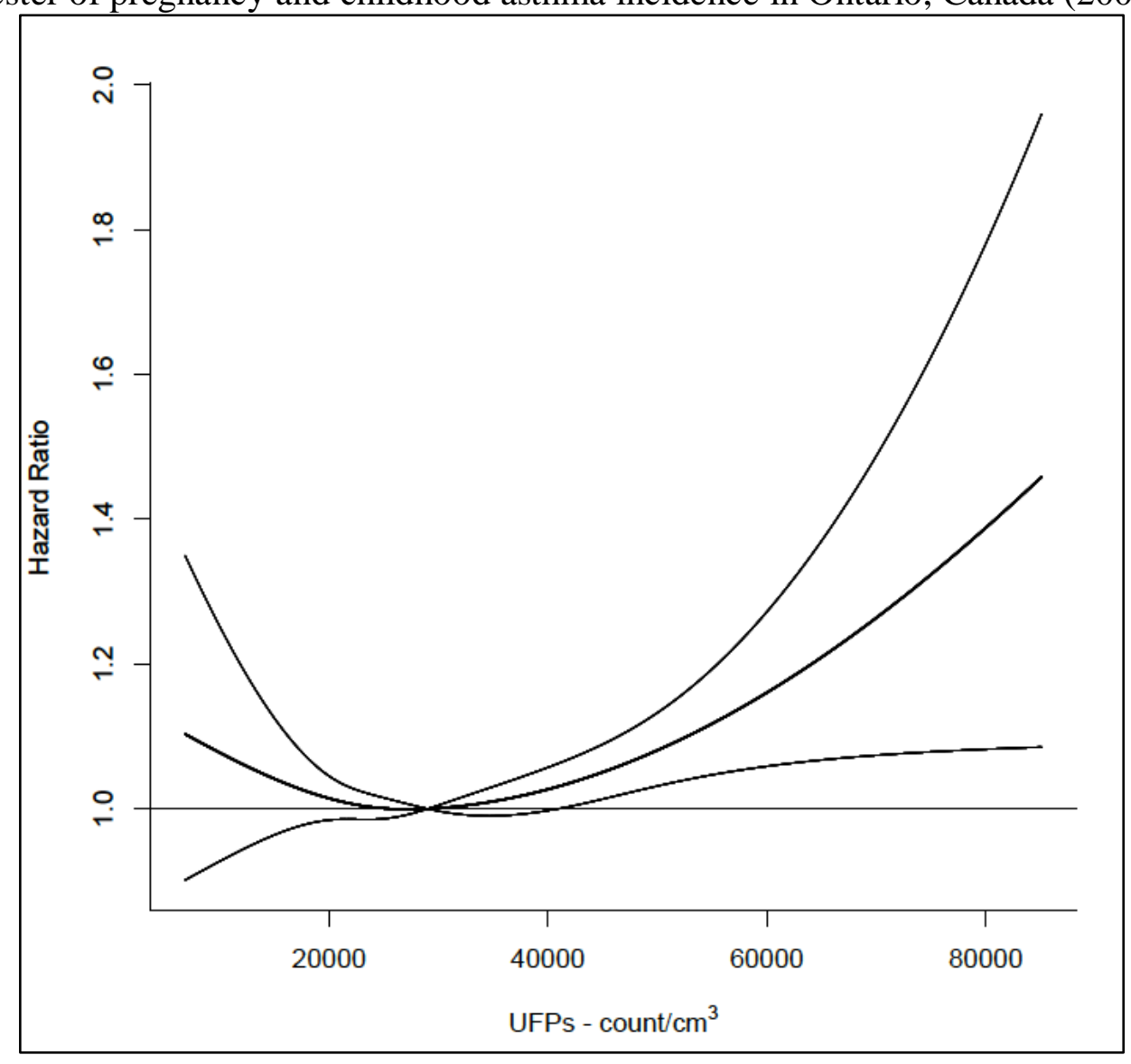

